Professor Mandelker's article provides another dimension to the analysis of planned unit developments. He cautions us to determine the broad social values that will probably be advanced by the building of planned unit developments before we decide upon the desirability and manner of changing our system of land use control. While he agrees with Professor Krasnowiecki that regulations should not be preset and that administrative agencies should have a considerable amount of discretion, Professor Mandelker believes that the courts should assume a more active role in reviezing decisions which involve matters of public policy.

\title{
REFLECTIONS ON THE AMERICAN SYSTEM OF PLANNING CONTROLS: A RESPONSE TO PROFESSOR KRASNOWIECKI
}

\section{Danter R. MaNDelker $\dagger$}

American land use and development controls have been oversimplified. We have tried to deal with extremely complex environmental problems by isolating from a stream of interacting variables those few that we felt could be manipulated with any chance of success. For example, initially the major function of zoning was the control of land use compatibilities. With time, however, it became obvious that zoning was not successful in dealing with the problem of nonconforming use. In order to correct this deficiency, we simply isolated other significant variables, and suggested improved methods of control. Currently, we are attempting to accommodate planned unit developments, which have been widely advertised as a concept that will lead to important improvements in residential development and design.

Having been led through the fire more than once, and having more than occasionally been burned in the process, the legal profession is now less willing to take zoning innovations on faith and is beginning to ask a number of basic questions about our system of planning administration. Thus, Professor Krasnowiecki's excellent article searchingly analyzes the role that planned development regulation should play in the constellation of land use controls. Since he is working within the limitations of the American legal system, Professor Krasnowiecki turns naturally to the controls afforded by the judicial process. His paper develops two interacting themes. On the one hand, he desires a system of control which maximizes the developer's freedom of choice by minimizing the legal impediments to planned

$\uparrow$ Professor of Law, Washington University, St. Louis. B.A. 1947, LL.B. 1949, University of Wisconsin; J.S.D. 1956, Yale University. 
unit development; while on the other hand, he feels the need for legal constraints which will keep the choice within bounds and prevent the developer from harming the physical environment. However, before I discuss his proposals, I want to raise a preliminary question which he has only suggested: What social values are we advancing when we encourage residential development at the planned unit scale?

\section{Social Purpose in Planned Development Regulation}

As Herbert Gans has pointed out, "physical planning has tended to provide greater benefits to those who already have considerable economic resources or political power." 1 For an illustration of Gans' point, we need look no further than the devices which suburban municipalities so frequently employ to maintain the exclusiveness of their residential communities. Gans also notes that American city planning has tended to be method-oriented rather than goal-oriented-in other words, planning has concentrated on techniques which distinguish it professionally from other disciplines, but which may or may not be geared toward solving problems that are new, urgent, and nontraditional. ${ }^{2}$ Therefore, it is not surprising that planned unit developments primarily involve a change in the method of land use. Whatever the present focus of the planners, however, we would be shortsighted if we were to evaluate planned unit developments without looking at the social results which they are likely to produce. The following examples illustrate my concern:

(1) The obstacles to efficient planned unit development, so well described by Professor Krasnowiecki, are sufficiently forbidding that the field will probably be dominated by large scale developers who have the financial capacity to assemble large tracts of land and make early and substantial commitments to site planning and improvements. While it is true that there is already a trend towards large scale development in standard lot by lot housing, it seems likely that planned unit developments will accelerate this trend. Therefore, we cannot evaluate planned developments without speculating about the environment which the large scale developer is likely to provide. I am suggesting, of course, that we question all the features of the product itself, from design to quality of construction.

(2) A further criterion for evaluating planned developments is to consider their impact on racial patterns in housing. Although residential integration has occurred more frequently in new developments, there is much to be said both for and against the likelihood that

1 Gans, Social and Physical Planning for the Elimination of Urban Poverty, 1963 WASH. U.L.Q. 2, 16.

$2 I d$. at 14,15 . 
planned unit developments will be an integrating force. On the negative side, there is the need to isolate the planned development from its surrounding area in order to create a buffer both against adjacent uses and objections from neighbors. Usually integration occurs by gradual infiltration from a contiguous area, and, therefore, this physical separation combined with a suburban location can be expected to work against successful racial integration. In addition, racial segregation will probably be reinforced by the likelihood that developers will build for the upper income market, a likelihood which is grounded upon the economic facts of the building business. Most planned unit developers contemplate a reduction in the size of individual lots in return for providing common open space. But reductions in conventional lot sizes are feasible only at low densities, given the traditional design of single family subdivisions. The traditional design could be altered, but experience with planned unit developments in some areas indicates that this change is not forthcoming. To reduce lot sizes any further in low income "tract" housing would require a revolution in building types and lot arrangements which the market is not ready to tolerate. Additional reasons why we can expect the planned unit developer to cater to the upper income market are the anticipation of an increasing affuence and a continuing pressure to liberalize mortgage terms, both conventional and FHA-VA. We must also take into account the ever increasing urban problems which put pressure on the upper income family to leave the cities. A significant number of home owners appear willing to buy the "protection" which the well insulated planned development will offer.

On the other hand, planned unit developments need not take the form of isolated enclaves of expensive homes. They can, for example, be built in urban renewal areas, and, if planned skillfully, can even be successfully constructed on a small scale. ${ }^{3}$ Furthermore, the volume builder who has the financial capacity to invest in planned unit development can best withstand the social and economic pressures that racial integration brings. Indeed, it can be argued that the newly built, large scale development provides the best opportunity for racial integration in housing, particularly because of the extended leverage of federal control through the Equal Opportunity in Housing order. ${ }^{4}$

Quite obviously the question of whether or not planned unit developments foster racial integration is extremely complex, and therefore it is difficult to draw a conclusion without more field data and

3 Although only peripheral to the racial issue, it is worth noting that with the right community attitude, more variety in housing types and an improvement in project design can also be achieved.

4 Exec. Order No. 11063, 27 Fed. Reg. 11527 (1962). 
a far more extensive analysis. I am only raising the question because it serves to illustrate the considerations I feel are important and which all too often have been ignored in the rush to adopt new methods.

\section{The Character of Planned Development Regulation}

Social issues must be identified not only for their broad value in advancing the goals of society, but also for determining the propriety of certain types of regulations and procedures. For example, if a " $m i x "$ in housing types were required in order to qualify for federal loans or guaranties for planned developments, ${ }^{5}$ we would be rather foolhardy to have a "mix" proposal reviewed by local authorities who represent a community with a history of exclusionary zoning. The state or local agency that should have the approval function in planned development regulation, and the limits that should be placed on neighbor objections and judicial review, should be inexorably bound to the policies which we are advancing and the prejudices we expect to encounter.

Broad policy issues are not nearly so critical when we focus our attention on the extent to which specific standards should be outlined in the zoning ordinance. I agree with Professor Krasnowiecki that if we were to preset detailed regulations the result would be a complex document which local communities might not only be reluctant to adopt but which they would find difficult to administer. Professor Krasnowiecki notes that the courts' desire to have the issues simplified for their review may underlie and explain traditional preset zoning regulations. I would like to elaborate on this point.

Critics of contemporary housing often forget that conventional lot regulations are utilized because they simplify the problems of control. It would be self-defeating merely to use the same types of regulations for planned unit developments. For example, the planned development ordinances that have been adopted frequently contain regulations for the spacing of buildings as a substitute for the more conventional yard requirements. These regulations either specify intricate building relationships or enact complex daylighting indices based on window area. I find these regulations difficult to justify. I doubt that they can be administered without the exercise of consider-

5 A provision which required the administrator to encourage a "mix" "whenever feasible in the light of current conditions" was present when the Federal Housing Act of 1965 was in bill form, but the section pertaining to loans and guarantees for planned developments was not part of the legislation finally enacted. Compare H.R. 5840,89 th Cong., 1st Sess. §201(c)(1) (1965), with §1004, 79 Stat. 463 (1965). The provision would have encouraged an economic "mix." No mention is made of a racial "mix." 
able administrative discretion, and I am sure that most builders will find them stultifying when they are applied.

The alternative to complex preregulation is to place considerable discretion in the hands of the approving agency. Professor Krasnowiecki takes the view that it would be desirable to reduce substantially both the scope of judicial review and the situations in which the neighbor is accorded standing. As no other method of review is substituted, an administrative decision to approve the planned unit development may go unchallenged. He does not discuss in detail the substantive standards that would be needed to guide the exercise of administrative power. From the tone of his paper, I get the impression that he considers this an impossible task. Therefore, the sum of his suggestions confers on an administrative board a totality of power which would insulate the developer, but might not protect the interests of the community.

On the issue of challenge, Professor Krasnowiecki's allusion to the English system needs correction. It is true, as he says, that objecting neighbors in England may not challenge the local authority's decision to permit development, but alternative forms of review are available which he neglects to mention. The most important of these is the overriding authority of the Minister of Housing and Local Government. The Minister must approve all community development plans, and any proposal which deviates substantially from a previously approved plan must be referred to him. ${ }^{6}$ In addition, the Minister has the power to call in applications for new developments, which means that on his own initiative he may pass on any proposal submitted anywhere. ${ }^{7}$ There are still other opportunities for review. Decisions to approve development are made initially by junior government districts, but they are subject to an ex parte administrative review (without a hearing) by the county planning authority. Neighbors have no right to insist on county review, but through their local councils they can make themselves heard, and with public notice of planning applications increasingly required by statute, they are more and more likely to do so. 8

In the absence of a comparable administrative system, I believe we need some method to trigger the judicial review of the local agency's decision to approve a planned development. So far the appeal by the objecting neighbor is the only method we have devised. I am surprised that any appeals are taken at all considering the obstacles to effective organization at the neighborhood level. I do not

6 Town and Country Planning Act of 1962, $10 \& 11$ Eliz. 2, c. 38, $\$ 5,13(1), 14$.

7 Town and Country Planning Act of 1962, 10 \& 11 Eliz. 2, c. 38, $\$ 22$.

8 See Town and Country Planning Act of 1962, 10 \& 11 Eliz. 2, c. 38, §15. 
mean to suggest, however, that I am satisfied with the neighboring challenger, for, on the contrary, his perspective is usually all too narrow. The problem of how to raise the important issues in zoning litigation is a continually perplexing one in our system, and certainly extends beyond the planned development context.

I have noted previously that the regulation of planned units is likely to require a reappraisal of the basic assumptions underlying our system of planning administration. That this reevaluation will be extensive is indicated by Professor Krasnowiecki's discussion of Eves. I believe that such a reappraisal is surely in order before we make any additional modifications. However, even if we manage to squeeze planned developments into our existing framework, as I regretfully imagine we will, our system of planning administration will look radically different after the effects of the planned development technique have been felt.

\section{The Role of the Courts in Reviewing Planned Developments}

Professor Krasnowiecki says that courts prefer to deal with crude categories of land uses and that they feel uncomfortable in making the sensitive decisions which planned unit development forces them to make. Moreover, by concentrating on procedures rather than on substance, he seems to imply that the merits of individual projects should not be subjected to judicial review. Indeed, he suggests that the usual objections by neighbors, which he incisively reduces to a demand for the status quo, are not justiciable.

Professor Krasnowiecki's analysis of the probable judicial approach to planned unit developments is novel and imaginative. His analysis is limited, however, to problems of equity, in other words, to the distribution of land resources among competing claimants. I am inclined to agree with him that perhaps these problems should not be justiciable. He does not, however, discuss the problem of goals, or the judicial role in the goal setting process, and these are the issues that I feel should be subject to judicial review. ${ }^{9}$

While I am puzzled by what the role of the courts should be in the land planning process, I think that the question is a good deal broader than the regulation of planned developments. At issue here is the need to shift from preset controls to ad hoc discretion, a need which planned development regulation has simply accentuated, and

9 Whether the courts favor the incremental extension over the isolated "island" is another question. The zoning of "spots" has been approved when it is justified by the needs of the entire community. I suspect that additions to commercial strips are more easily explained by the inherent instability of a land use pattern in which the lines between commercial and residential zones are difficult to maintain, given the pressures for conversion to commercial uses. 
which, I believe, requires a corresponding change in the judicial role. No matter how specific the standards under which planned developments are to be approved, the need for discretionary decision making requires that policy, to some extent, will be made with each approval. ${ }^{10}$ The prevailing attitude of the courts would lead me to believe that they would prefer not to review these policy elements in the decision, and it is this possibility that I find most distressing. I am heartened, however by those court decisions which have upheld the exclusion of a particular land use because the service in question was provided elsewhere in the region, even though not present in the municipality. ${ }^{11} \mathrm{By}$ an extension of this same approach, the courts could indicate the factors which should be considered by a municipality when it approves or disapproves a planned residential development. Nothing inherent in the judicial process prevents the courts from setting these limits. That they have failed to develop helpful guides in spot zoning and similar cases does not mean that it would be futile for us to rely upon them.

\section{Some Predictions About a Changing System}

The legal system has difficulty in responding when social change occurs rapidly and moves in several directions at the same time. Yet this is just the problem we face in the field of land use controls. Urban renewal projects, highway interchange areas, planned developments, and new towns all require the coordination of development patterns in a single tract on a large scale. It is obvious that our planning controls will have to make a series of fundamental adjustments in order to respond to these changes.

In the suburban areas, large scale developments often demand environmental decisions that affect more than one municipality, so that planned development will increasingly require controls at the regional and state levels. ${ }^{12}$ Meanwhile, decisions pertaining to particular de-

10 Further examination of the English system underscores this point. Under that system, all new development proposals are subject to individualized review under the very general terms of the community's development plan. One factor which is controlled by the development plan is project density, but the development plan is not binding under the English system. Densities in any event are shown as averaged figures applicable to entire neighborhoods, and their calculation in detail leaves much to the discretion of the planning authority. The local authority's decision on project density thus contains policy elements to the extent that the density allowed by the development plan can either be varied from the norm or adjusted to fit subneighborhoods. If the local planning authority refuses to permit the development, for density or other reasons, its decision is administratively appealable to the Minister on its merits, but the Minister's decision is not reviewable judicially. We are certainly tending in the same direction, except that our procedures for administrative review are not as well developed. 107.

11 See Note, Zoning: Looking Beyond Municipal Borders, 1965 WasH. U.L.Q.

12 One tiny St. Louis County municipality consists in large part of a highway interchange. 
velopment projects will tend to be made at the time the developer makes his application, under broad discretionary standards rather than preset regulations. We then must decide, as the English already have, whether or not the judiciary will play a significant role in the regulation of planning. Finally, the scale of the new developments will lead to more state, if not federal, intervention both in regulation and in financial assistance. This increased intervention will lead in turn to substantive conditions designed to advance state and federal policy. I have already suggested that the conditions which will accompany federal financial aid may alter the questions we will have to ask when deciding on the acceptability of residential planned developments. We must focus on these larger issues and not, as some planners would urge, on the immediate mechanics of development controls. 